\title{
Digital transformation
}

\author{
Jörn Kleinert ${ }^{1}$
}

Published online: 8 February 2021

(c) The Author(s) 2021

The "Digital Transformation" was the topic of the 101. Annual Meeting of the Austrian Economic Association (NOeG 2019), which took place at the University of Graz on April 25-26, 2019. It was an attempt to spur the debate about digitalization in Austria and study the long-run process from different perspectives. Many observers shared the feeling that Austria is lagging behind in this trend, something that has found some support during the Corona lock-down in Spring 2020. Thus, it was time to discuss digitalization issues. The "Digital Transformation" is the challenge in the years to come. In Austria we have a minister for Digital and Economic Affairsmind the ordering - which points to the importance of the change we expect in the economy. Moreover, having a ministry makes the claim that digitalization can be and must be managed. The change in economy and society is not stoppable but can be managed in the way that it is in line with conceptions of the people forming the society. That requires many institutional adjustments, continuous work and a longrun perspective.

Yet, societal and economic changes of the scope of the digitalization usually start less noticed and slowly but gain strength over time until they are the dominating process. We might be in the process of a digital transformation already for a while and with hindsight in some years, we might realize what had already achieved in 2019. Many developments are much clearer to describe with hindsight than in the middle of the process or even only at its beginning. The discussions at the meeting wanted to contribute to structuring the transformation by presenting evidence on various elements of the change, new trends and problems, by discussing the evidence and making suggestions to politics and public. In this way economists can participate in forming what will be the society in and ,after" a digital transformation.

The different evidence included various fields of economics from monetary policy in times of cryptocurrencies and Fin-techs, labor market issues such as crowd working platforms, gender issues to innovation and growth. The regional perspective of Austria in Europe or smaller, sub-national regions in Europe has also been a topic. For the Styrian region, which also hosted a dinner for the participants of the meeting, the digital transformation is just the next version of an ongoing

Jörn Kleinert

joern.kleinert@uni-graz.at

1 Institute of Economics, University of Graz, Universitätsstraße 15/F4, 8010 Graz, Austria 
structural change which has focused in the 1980s and 1990s on privatization and organizational change within firms and industries, in the 2000s on internationalization and the integration in global value chains and since some years on the digital transformation.

While not that high on the political agenda at the current pandemic situation, the digital transformation has been boosted in the last month. Lock-down situations with home office, home schooling and distance learning have shown (i) how powerful the tools are which are based on digital technologies and, (ii) how much change in equipment, organizational structure and knowledge is still needed to make best use out of them. While technological change is an ongoing process that will never end, some distinct periods mark watersheds of dominating phenomena characterizing particular time periods. The exogenously enforced organizational change in 2020 might become the event that fosters the digital transformation by requiring effort from many different actors.

Firms are particularly challenged by the new chances and requirements which come with the digital transformation. Digitalization will reduce market entry barriers in several sectors and changing skill requirements will offer the chance to contest markets that have been rather stable before or to establish new markets. Entrepreneurship might become a much more important feature in the times to come as has been argued several times at the conference particularly with respect to digitalization but also in reference to other branches.

The new entrepreneurship is one feature of a broader change in production in the digital transformation towards the use of more automated production tools. This will affect the relationship between employers and employees and the structure of the labor force. In their study on the „Industry 4.0-The Future of Austrian Jobs”, Bernhard Mahlberg, Peter Haiss and, Daniel Michlitz discuss the available evidence on the role of computerization in production of goods and services on expected available jobs in Austria and their characteristics. The paper broadens the definition of job risks and applies this more lenient definition to the assessment of Austrian workforce data of the mid 2010s. The authors predict significant change in the jobs for about half of Austrian employees within the next two decades.

Solow's saying that computers can be seen everywhere but in the productivity statistics points to the fact that productivity changes on the micro-level are not warranted and if they arise they are often hard to detect. Moreover, productivity growth often only materializes after some time. Andreas Eder, Bernhard Mahlberg and, Bernhard Stürmer offer some evidence from another sector of rapid change in the last decades (and urgent need for it): energy supply. In their analysis on „Measuring and explaining productivity growth of renewable energy producers: An empirical study of Austrian biogas plants" the authors assess the change in productivity of 65 Austrian biogas plants from a balanced sample from 2006-2014. They use data envelopment analysis and the resulting Malmquist index to measure productivity and its change. They split this change in three components: technical change, efficiency change and scale change. Scale change turns out to be particularly important, an effect which is driven only by small plants.

While having received quite some attention, the digitalization of money (currency, cash) and the research on it is still in its infancy. Helmut Stix summarizes, 
discusses and, assesses information on crypto-asset ownership in Austria drawn from surveys conducted in 2018 and 2019. According to his paper „Ownership and purchase intention of crypto-assets-survey results" only $1.5 \%$ of the survey population owned crypto-assets at the time. Results are therefore taken with care, but they are nevertheless interesting and likely to be telling in various respects: (i) it is more the crypto-assets than the crypto-currency that is held, (ii) more informed and technology-oriented people own crypto-assets, (iii) trust is not an issue in holding crypto-assets and (iv) the higher volatility is taken into account by investors.

The papers in this special issue give some insight in the large changes that will come with the digital transformation in different spheres affecting many domains of the society. Whether the digital transformation will have an impact comparable to that of the industrial revolution where economy and society changed drastically could not have been answered and must be left for the future to tell and further research.

Open Access This article is licensed under a Creative Commons Attribution 4.0 International License, which permits use, sharing, adaptation, distribution and reproduction in any medium or format, as long as you give appropriate credit to the original author(s) and the source, provide a link to the Creative Commons licence, and indicate if changes were made. The images or other third party material in this article are included in the article's Creative Commons licence, unless indicated otherwise in a credit line to the material. If material is not included in the article's Creative Commons licence and your intended use is not permitted by statutory regulation or exceeds the permitted use, you will need to obtain permission directly from the copyright holder. To view a copy of this licence, visit http://creativecommons.org/licen ses/by/4.0/.

Publisher's Note Springer Nature remains neutral with regard to jurisdictional claims in published maps and institutional affiliations. 